\title{
Cyclospora: another "new" pathogen
}

\author{
"The list of described species of parasitic animals and plants \\ to which man is liable is already a long one, but, \\ nevertheless, in different parts of the world, others will yet \\ be discovered." \\ Joseph Leidy, A Flora and Fauna Within Living Animals,
}

Since the introduction of methods for the laboratory diagnosis of cryptosporidiosis, various acid-fast oocyst-like forms have been recognised in faeces, especially when stained by the modified Ziehl Neelsen stain. They have often been mistaken for the oocysts of cryptosporidia and have variously been described as cryptosporidium-like bodies, coccidian-like, fungal spores, Blastocystis spp., cyanobacteria (blue-green alga)-like. ${ }^{1-9}$ Some are undoubtedly artefacts or other bodies of no significance. ${ }^{9-10}$ However, one of these bodies has now been definitively identified as the oocyst stage of a coccidian protozoan parasite, Cyclospora. ${ }^{11-14}$ This genus is common in nature, but the species identified in man differs from other Cyclospora spp. and has tentatively been named Cyclospora cayetanensis n.sp. ${ }^{11,13}$ Descriptions in some earlier reports are not sufficiently detailed for conclusive retrospective identification, but the pictures and other details suggest that the organism involved, in at least some instances, is likely to be the same species. The oocysts have been recognised in the faeces of patients from Peru since $1985 .{ }^{11,13}$ They were first noted in the UK at about the same time in travellers returning from the tropics, although their identity was uncertain. However, the earliest description of human infection with cyclospora-like organisms was from Papua New Guinea as long ago as $1979 .^{15,16}$

The genus Cyclospora was first described in Old World moles, by Schaudinn at the turn of the century. Related species were described subsequently in rodents, reptiles, birds, and even myriapods (centipedes, etc). ${ }^{17,18}$ Cyclosporans are common in British moles and are spheroidal and larger than those found in man (unpublished observation). ${ }^{18,19}$ Coccidia may complete their full life-cycle within a single host, or require a second host, often in a herbivore-carnivore cycle, as with Toxoplasma. Cryptosporidia need only a single host but, unlike many coccidia, Cryptosporidium parvum is characteristically not host and tissue specific. These aspects of the life cycle of the cyclosporan in man are uncertain but an apparent association with undercooked pork in Papua New Guinea ${ }^{15}$ suggests the possibility of an indirect life cycle. Cyclospora spp. have a typical apicomplexan, coccidian structure, the genus and its species being defined in particular by oocyst development and morphology. ${ }^{13,17,20,21}$ The period required for external maturation (sporulation) of excreted oocysts varies with the species, and possibly also with environmental conditions, from a few days to weeks, and size and shape also vary.

The main site of infection for Cyclospora cayetanensis is probably the small intestine and possibly the colon. There is evidence from some animal studies on other cyclosporan species of multiple organ involvement, including infection of the liver and bile duct. ${ }^{18}$ The merozoites of some species have been shown to be resistant to the effects of macrophage enzymes and haematogenous spread is, therefore, a possibility. Unlike cryptosporidia, cyclospora appear to develop in a fully intracellular and intracytoplasmic location; some species multiply in an intranuclear location. In human jejunal biopsy specimens examined by light and electronmicroscopy, Bendall and colleagues $^{12}$ described endogenous stages mid-way between the nucleus and the brush border of enterocytes. Much work remains to be done to define the life cycle and animal models need to be developed.

In the species found in man the oocyst is round or slightly ovoid with a diameter of $8-9 \mu \mathrm{m}$ which, when sporulated, contains two sporocysts, each containing two typical apicomplexan sporozoites of $1.2 \times 9 \cdot 0 \mu \mathrm{m}$. The oocyst morphology is different from all other cyclosporans so far described. ${ }^{13}$ Unlike cryptosporidia, the oocysts of cyclospora sporulate only after excretion. At first they have a characteristic morular (mulberry) inner structure which is seen readily in wet preparations examined by phase or differential interference contrast microscopy. Incubation under controlled conditions permits development of two sporoblasts and subsequently of the two sporozoites within each. The final stage of excystation is achieved in vitro with difficulty but is essential in defining the identifying characteristics of the parasite..$^{13,17,20,21}$

Cyclospora-like organisms have been detected in patients from many countries including Nepal, Indonesia, Southern and Central America and Turkey. No reports have been published so far from subSaharan Africa or Australia. Infection occurs in persons of all ages but is most commonly found among travellers (who tend to be mainly adults) and in children and adults living in developing countries. Apparently indigenous cases identified in the $\mathrm{USA}^{5,8,22}$ and in the UK were, unlike cryptosporidiosis cases, mostly in adults. The difference in the age distribution of patients from developed countries may result from selective examination or from 
exposure being restricted mainly to adults. The occurrence and role of person-to-person transmission is currently uncertain.

The reservoir of infection has not yet been identified and the host range of the species infecting man is not known but there is some epidemiological evidence for transmission by water: peak incidence occurs in the rainy season and there is evidence of association with consumption of untreated water or foods contaminated by polluted water. Organisms resembling cyclospora have been described in drinking water and lettuce in Nepal. ${ }^{5,14}$ However, preliminary attempts in Nepal to detect cyclospora in the water supply of sporadic cases, as well as in a wide variety of associated animal species, were unsuccessful (Whitworth, personal communication).

Is Cyclospora a human pathogen? Studies from $\mathrm{Nepa}^{6,14}$ suggest that cyclospora is significantly associated with diarrhoea and with a protracted illness; cessation of oocyst excretion appears to follow resolution of diarrhoea. Recognised co-pathogens were usually excluded although mixed infections have been described ${ }^{12,14,23}$ symptomless excretion appeared to be uncommon. $\mathrm{Up}$ to $7 \%$ of American workers acquired the infection in Nepal during a study period. Prolonged stay seemed to be associated with the development of protection. Sero-conversion during infection and controlled evidence of therapeutic response have yet to be reported although some cases seem to respond to treatment. Without controlled trials, it is not possible to exclude coincidental resolution, or the effect of successful eradication of a copathogen. Nonetheless, the evidence strongly suggests that this organism is indeed a newly recognised enteric pathogen.

Symptoms of infection include watery diarrhoea, sometimes explosive in onset, lasting $c .6-7$ weeks (range 1-8 weeks). There may be a prodromal malaise with anorexia, abdominal cramps and marked weight loss; flatulence, bloating and dyspepsia may occur, suggesting malabsorption. Inapparent or asymptomatic infection has been described in indigenous subjects in developing countries, probably reflecting recurrent re-infection in the immune. As with most newly recognised pathogens, the occurrence of less protracted illness may become more apparent as knowledge of the infection increases.

Chronic infection has been reported in some AIDS patients but there is no evidence to show that immunocompromised patients are at greater risk of infection or suffer more severe disease. However, until the natural history of the parasite is defined, it is not possible to assess the frequency with which such subjects are likely to be exposed to infection.

Treatment is largely symptomatic and aimed primarily at rehydration. Little is known about the sensitivity of cyclospora to antimicrobial agents but some anecdotal evidence suggests that co-trimoxazole may be useful. ${ }^{24}$ Prevention is likely to be achieved best through limiting the opportunity for ingestion of faecally contaminated material, by boiling or properly filtering water for consumption, and by avoidance of uncooked foods in high risk areas.

The oocysts are excreted in stools in large numbers during the acute stage and variably thereafter; they can be detected by modified Ziehl-Neelsen staining ${ }^{9}$ although the acid-fast staining is very variable; the refractile morula can often be seen in unstained oocysts amidst the counterstained material. Oocysts are 8-9 $\mu \mathrm{m}$ in size and have a mottled surface appearance. When fresh stool wet-mount preparations are viewed by phase or differential interference contrast microscopy, the oocyst wall appears to be hyaline, smooth and entire; the internal morula can be seen as a collection of refractile, membrane-bound, spherical bodies, $1-2 \mu \mathrm{m}$ in size, within the wall and may have a slightly greenish hue. ${ }^{12,13}$ In older or preserved specimens the contents may have coalesced into a smaller number of globular bodies and the remaining contents appear more granular. By fluorescence microscopy they may show blue autofluorescence of the oocyst wall, although this is sometimes weak or variable.

The identification of a newly recognised cyclosporan parasite of man, is exciting even if the infection is shown to be of restricted importance in developed countries. Clarification of the taxonomy and of the clinical and epidemiological features is continuing and we can expect many further reports. However, many laboratories now perform stool concentration, and even wet-film examination, on only a few selected specimens as a result of increasing constraints. ${ }^{25}$ The epidemiology and significance of these organisms will remain uncertain if this continues. Definitive identification in the routine laboratory remains problematic especially if laboratories fail to confirm the measurement of putative oocysts ${ }^{9,10}$ cyclosporans will continue to be overlooked or their identity confused. Monoclonal antibodies will become more widely available in due course, but they are expensive and fluorescence microscopy is not always available. The history of the recognition of cyclospora is a case study in mistaken identities. Ashford ${ }^{15}$ drew attention in 1979 to the ease with which the oocysts could be confused with fungal spores. Other currently unidentified bodies will be found from time to time and might be suspected of being associated with symptoms. All cryptosporidium-like bodies, we know, are not $C$. parvum; there are also cyclosporan-like bodies-let the microscopist beware.

D. P. Casemore PHLS Cryptosporidium Reference Unit, Public Health Laboratory, Glan Clwyd District General Hospital, Bodelwyddan, Rhyl, Clwyd LL18 5UJ. 


\section{References}

1. Soave R, Dubey JP, Ramos LJ, Tummings M. A new intestinal pathogen. Clin Res 1986; 34: 533A. (Abstract).

2. Hart AS, Ridinger MT, Soundarajan R, Peters CS, Swialto AL, Kocka FE. Novel organism associated with chronic diarrhoea in AIDS. Lancet 1990; 335: 169-170.

3. Long EG, Ebrahimzadeh A, White EH, Swisher B, Callaway CS. Alga associated with diarrhea in patients with acquired immunodeficiency syndrome and in travellers. $J$ Clin Microbiol 1990; 28: 1101-1104.

4. Long EG, White EH, Carmichael WW et al. Morphologic and staining characteristics of a cyanobacterium-like organism associated with diarrhea. $J$ Infect Dis 1991; 164: 199-202.

5. Centers for Disease Control. Outbreak of diarrheal illness associated with cyanobacteria (blue-green algae)-like bodies-Chicago and Nepal, 1989, 1990. MMWR 1991; 40: 325-327.

6 Shlim DR, Cohen MT, Eaton M, Rajah R, Long EG, Ungar BLP. An alga-like organism associated with an outbreak of prolonged diarrhea among foreigners in Nepal. Am J Trop Med Hyg 1991 ; 45: 383-389.

7. Anon. Diarrhoeal diseases: outbreaks of diarrhoeal illness associated with cyanobacteria (blue-green algae)-like bodies. World Health Organization Weekly Epidemiological Record. 1991; 66: 241-243.

8. Wurtz RM, Kocka FE, Peters CS et al. Clinical characteristics of seven cases of diarrhea associated with a novel acid-fast organism in the stool. Clin Infect Dis 1993; 16: 136-138.

9. Casemore DP. The laboratory diagnosis of human cryptosporidiosis. Broadsheet No 128. J Clin Pathol 1991; 44: 445-451.

10. Casemore DP. A pseudo-outbreak of cryptosporidiosis. PHLS Communicable Disease Report, Review no. 6. 1992; 2: R66-R67.

11. Ortega YR, Sterling CR, Gilman RH, Cama VA, Diaz F. Cyclospora cayatanensis: a new protozoan pathogen in humans. Proc Am Soc Trop Med Hyg 1992; 210: abstract.
12. Bendall RP, Lucas S, Moody A, Tovey G, Chiodini PL. Diarrhoea associated with cyanobacterium-like bodies: a new coccidian enteritis of man. Lancet $1993 ; 341: 590-592$.

13. Ortega YR, Sterling CR, Gilman RH, Cama VA, Diaz F. Cyclospora species - a new protozoan pathogen of humans. N Engl J Med 1993; 328: 1308-1312.

14. Hoge CW, Shlim DR, Rajah R et al. Epidemiology of diarrhoeal illness associated with coccidian-like organism among travellers and foreign residents in Nepal. Lancet 1993; 341 : $1175-1179$.

15. Ashford RW. Occurrence of an undescribed coccidian in man in Papua New Guinea. Ann Trop Med Parasitol 1979; 73 : 497-500.

16. Ashford RW, Warhurst DC, Reid GDF. Human infection with cyanobacterium-like bodies. Lancet 1993; 341: 1034.

17. Levine ND. Taxonomy and life cycles of coccidia. In: Long PL (ed) The biology of the coccidia. London, Edward Arnold. 1982: 1-33.

18. Mohamed HA, Molyneux DH. Developmental stages of $C y c$ lospora talpae in the liver and bile duct of the mole (Talpa europa). Parasitology 1990; 101 : 345-420.

19. Duszynski DW, Wattam AR. Coccidian parasites Apicomplexa eimeriidae from insectivores IV. Four new species in Talpa europaea from England UK. J Protozool 1988; 58: 58-62.

20. Manwell RD. Coccidia. In: Introduction to protozoology. London, Edward Arnold. 1961: 515-538.

21. Chobotar B, Scholtyzek E. Ultrastructure. In: Long PL (ed) The biology of the coccidia. London, Edward Arnold. 1982: 101-165.

22. Hale D, Aldeen W, Carroll K. Diarrhea associated with cyanobacteria like bodies in an immunocompetent host. JAMA 1994; 271: 144-145.

23. Anon. Diarrhoea associated with Cyclospora species. PHLS Communicable Disease Report 1993; 3: 103.

24. Madico G, Gilman RH, Miranda E, Cabrera L, Sterling CR Treatment of cyclospora infections with co-trimoxazole. Lancet 1993; 342: 122-123.

25. Casemore DP, Roberts C. Guidelines for screening for Cryptosporidium in stools: report of a joint working group. J Clin Pathol 1993; 46: $2-4$. 